\title{
Design and Performance of a Novel Spillway Turbine
}

\author{
Filipa Adzic ${ }^{1}$, Thorsten Stoesser ${ }^{2}$, Emily Morris ${ }^{3}$, Stefan Runge ${ }^{1}$ \\ ${ }^{1}$ Hydro-Environmental Research Centre, Cardiff University, Cardiff, Wales, UK \\ ${ }^{2}$ Department of Civil, Environmental and Geomatic Engineering, University College London, London, UK \\ ${ }^{3}$ Emrgy Inc., Atlanta, GA, USA \\ Email: t.stoesser@ucl.ac.uk
}

How to cite this paper: Adzic, F., Stoesser, T., Morris, E. and Runge, S. (2020) Design and Performance of a Novel Spillway Turbine. Journal of Power and Energy Engineering, 8, 14-31.

https://doi.org/10.4236/jpee.2020.85002

Received: February 28, 2020

Accepted: May 25, 2020

Published: May 28, 2020

Copyright $\odot 2020$ by author(s) and Scientific Research Publishing Inc. This work is licensed under the Creative Commons Attribution International License (CC BY 4.0).

http://creativecommons.org/licenses/by/4.0/

\begin{abstract}
The high-speed supercritical flow in steeply sloped channels contains a significant amount of hydro-kinetic energy. A novel, horizontal axis, spillway turbine as presented in this paper attempts to convert that energy into electricity. We report on the turbine's design and experimental testing. Its intended use is in low-head, low-flow, manmade, concrete-lined channels such as chutes, spillways and other similar steeply sloped open-channels. The design lends itself from an impulse turbine runner but without a pipe or a nozzle. The spillway turbine consists of 2 main components: 1) the runner and 2) an accelerator channel that directs the water towards the runner's blades. The runner, once fitted with Pelton-inspired "cup inserts" shows performance improvements both in terms of efficiency and specific speeds. The specific speed and the speed factors calculated confirm that this novel spillway turbine runner can be categorized as an impulse turbine. The maximum efficiency obtained during laboratory testing is $43.4 \%$ and hence competes well with standard hydrokinetic turbines.
\end{abstract}

\section{Keywords}

Hydro-Turbine, Spillway-Turbine, Micro-Hydro, Horizontal-Axis, Impulse, Low-Head

\section{Introduction}

The world population has reached 7.2 billion in 2014 and it is predicted to reach approximately 9.6 billion by 2050 if current growth trends are applied [1]. Moreover, constant and rapid development of technology increased energy demands and energy dependence of the modern society significantly. Both of these 
factors led to a noteworthy increase of carbon emissions and can be directly linked to climate change.

Concerns about modern society's effect on climate change have been addressed in several international agreements. The Paris Agreement [2] signed by almost 200 countries, put pressure on involved parties to reduce greenhouse gas emissions and keep global temperatures in check. The European Union Directive from 2009 [3] set the objective to produce at least $20 \%$ energy from renewable energy sources by 2020. This framework was updated in 2014 proposing to increase energy production from renewable sources to at least $27 \%$ by 2030 [4]. Therefore, the investment into extracting energy from renewable energy sources, rather than fossil fuels, is highly encouraged.

Hydropower is a well-established renewable energy source, providing $71 \%$ of all renewable energy sources in 2016, and contributing to $16.4 \%$ of the world's electricity needs [5]. The majority of investments are directed towards large hydropower plants as they are the biggest contributors of electricity produced from water sources. High or medium head turbines such as Pelton, Kaplan or Francis turbines are mostly used in these large scale projects and have been established for decades.

Although hydropower is considered one of the cleanest forms of energy, questions are raised about social and environmental impacts in regions where large-scale hydropower plants were built. In the past six decades, between 40 and 80 million people have been moved from their homes as a direct result of large hydropower projects [6]. Also, large hydropower projects are known to impoverish river ecosystems considerably.

Having clean energy extraction from water, with minimal disruption to local life and ecosystems resulted in smaller scale hydropower developments becoming increasingly popular. This triggered a growth in new turbine design research, with the intention of placing such turbines in low head streams or man-made channels.

The spillway turbine reported on here is a low head, low discharge impulse turbine, intended for use in chutes, spillways or other similar, steeply-sloped, concrete-lined channels. This turbine design is very attractive due to its low production cost, ease of installation, manufacture and portability. The spillway turbine system consists of the runner and the accelerator channel(s), which is (are) used to direct the flow towards the blades. Only minor civil work and site adjustments will be required for the installation because the need for a nozzle and therefore a pipe has been eliminated, as the accelerator channel is envisioned to direct the flow to the runner.

In this paper we report on the design and experimental performance testing of the turbine runner and accelerator channel. The laboratory testing is completed in the Hydro-Environmental laboratory at Cardiff University. The objectives are to proof the concept of the design and quantify the turbine's performance in terms of power coefficient for various design variations. 


\section{Background}

The predecessor of modern hydraulic turbines, the water wheel, was invented in the $1^{\text {st }}$ century BC [7]. The water wheel was of great importance in the industrial sense as it was used for many different purposes, from grinding grain to cotton clothes manufacturing. The biggest industries around the world were dependent on the efficiency of water wheels in $19^{\text {th }}$ century. The water wheel inspired new and innovative turbine designs such as the first reaction turbine developed in England in 1744 which influenced the development of the Francis turbine in 1855 [8]. Modern Francis turbines are most widely used and are installed in the largest hydropower plants such as Three Gorges Dam [9], Grand Coolee Dam and Itaipu Dam [10]. The market for new turbines developed after the notation that turbines such as the Francis turbines do not perform well in very high head or low head conditions. Kaplan or Bulb turbines are most commonly used for low head conditions and are also classified as reaction turbines. As reaction turbines such as Francis operate well for medium but not very high head flows, impulse turbines were developed for use in such conditions. The principal difference between reaction and impulse turbines is in the way the flow energy is transferred to the runner. In reaction turbines, flow energy is partly converted to the kinetic energy but the flow pressure energy also has an effect on the impeller. In impulse turbines, water energy is completely converted to kinetic energy and the pressure energy does not have an effect on the runner [11]. Impulse turbines were invented at the end of $19^{\text {th }}$ century for use in very high head flows. The most researched and used of these, that has become a synonym for high head turbines, is the Pelton wheel. Turgo and Cross-flow turbines are other renowned impulse turbines.

\subsection{Motivation and Principles behind the Spillway Turbine Design}

The motivation for the development of the spillway turbine comes from the idea of having a turbine that can be placed in a stream without extensive civil construction and installation work and without significant disruption of the local ecosystem. The spillway turbine is intended to be an impulse turbine with the design inspired by the shape of Savonius hydrokinetic turbine shown in Figure 1 and on a Pelton wheel bucket, the flow velocity components of which are presented in Figure 2.

If considering frictional flows, the influences of Coriolis and centrifugal forces can be neglected comparing to the contributions of the frictional forces and the relative velocity is majorly affected by flow friction [13]. Similarly, the resulting impact force is significantly greater than Coriolis and centrifugal forces. The impact force appears due to the flow experiencing a sudden change in flow direction due to bucket curvature [14]. Hence, bucket design has a major influence on the performance of the turbine as positive work from forces should be maximised whilst minimising losses due to friction [15]. 


\subsection{Application Sites}

The spillway turbine is intended for use in manmade steeply-sloped channels such as chutes, spillway, etc. A spillway is a channel that ensures a safe transition of water from a reservoir to a stream [16] and the flow over a spillway can be classified as a super critical shallow flow. Examples of existing spillways include the Alqueva Dam spillway in Portugal [17] and Llyn Brianne spillway in Wales [18], both shown in Figure 3. Spillways are a common occurrence in reservoir and dam schemes.

If the spillway is large in length, it would be possible to place two or more turbines in series. This would maximise the usage of flow power and therefore result in higher energy extraction. The design scaling and adjustments would be recommended for each application site individually.

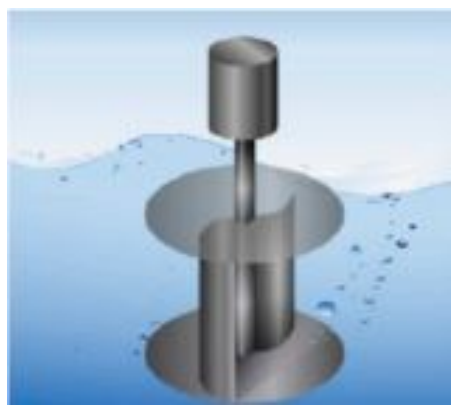

Figure 1. Hydrokinetic savonius rotor [12].

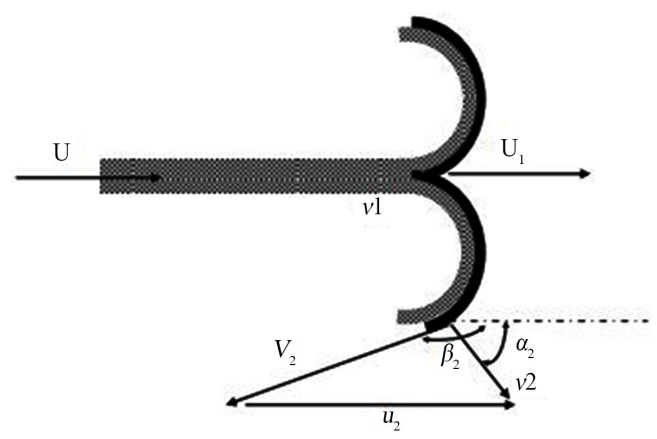

Figure 2. Velocity components of flow inside a Pelton bucket [15], where $\mathrm{U}$-velocity of jet, $\mathrm{U}_{1}$-velocity of the Pelton runner, $\mathrm{v}_{1}$-absolute velocity of water at the entrance to the bucket, $\mathrm{V}_{2}$-relative velocity of water at the exit from the bucket, $\mathrm{v}_{2}$-absolute velocity of water at the exit from the bucket.
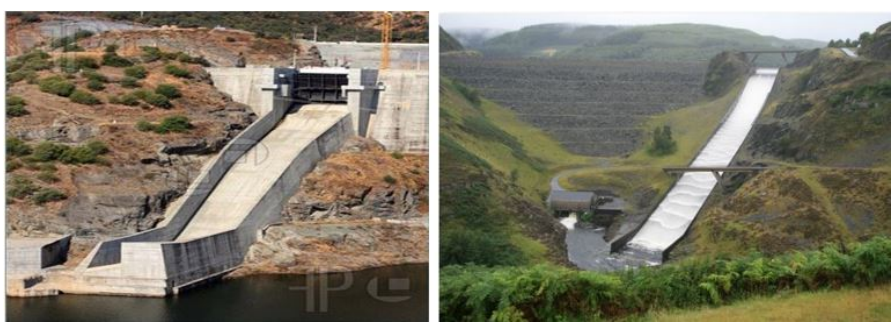

Figure 3. LHS, Alqueva Dam spillway, Portugal [17]. RHS, Llyn Brianne dam spillway, Wales [18]. 


\section{Design of the Spillway Turbine}

The spillway turbine design consists of two components, the runner and the accelerator channel. The biggest challenge in the spillway turbine design is to achieve good performance in very low head and low flow conditions. The need for a nozzle is eliminated as this would imply an increase in civil works. Instead, an accelerator channel is used to lead the flow towards the cups of the runner which significantly reduced installation, maintenance and production difficulty and costs.

\subsection{The Runner Design}

The runner was designed in such a way that different design variations can be tested with minimal structural changes. The basic runner design with no inserts is shown in Figure 4.

The runner's shaft is a stainless steel, $0.02 \mathrm{~m}$ diameter rod. The acrylic disks, $0.01 \mathrm{~m}$ thick were placed on both sides of the runner to protect it from side friction and to deliver structural stability to the system, while allowing to observe from the outside how the water interacts with the blades. The disks placed on the runner have a diameter of $0.2 \mathrm{~m}$ and are attached to the runner with 24 socket head cap screws on each side. The runner has 6 blades is $0.3 \mathrm{~m}$ wide with a diameter of $0.2 \mathrm{~m}$. The basic runner design is then modified by implanting 2 cup or 4 cup inserts into the runner. Detailed CAD drawings of both inserts are shown in Figure 5 and Figure 6.

The runner and the cup inserts are made of polyamide powder with a 3D printing technique called selective laser sintering (SLS). This production technique is based on a laser bringing powder material close to its boiling point and the heating of the powder particles results in formation of a solid shape. Synthetic laser sintering allows for quick and cheap production of the runner and the "cup inserts" and therefore it is chosen as a production method. Alternatively, the runner could have been manufactured from CNC machining of a solid block of material (e.g. aluminium or high-performance plastic), most likely the method of choice for real-world installations of the system.

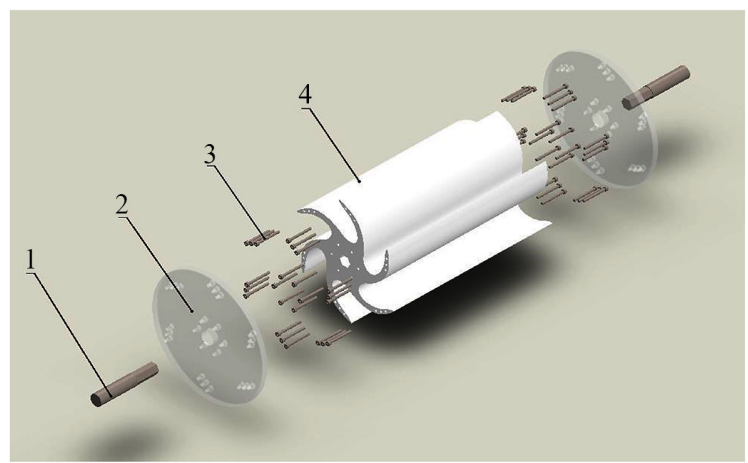

Figure 4. Exploded view of the runner with no inserts, 1-runner shaft, 2-acrylic disk, 3-screws, 4-runner blades. 


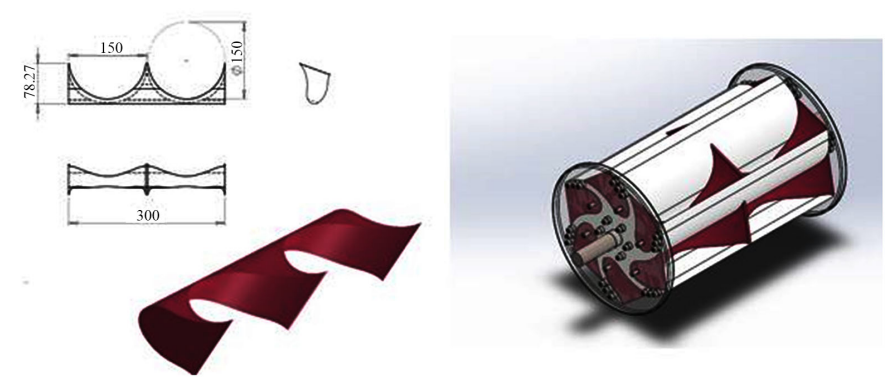

Figure 5. Drawing of the 2 cup insert and runner with 2 cup inserts.
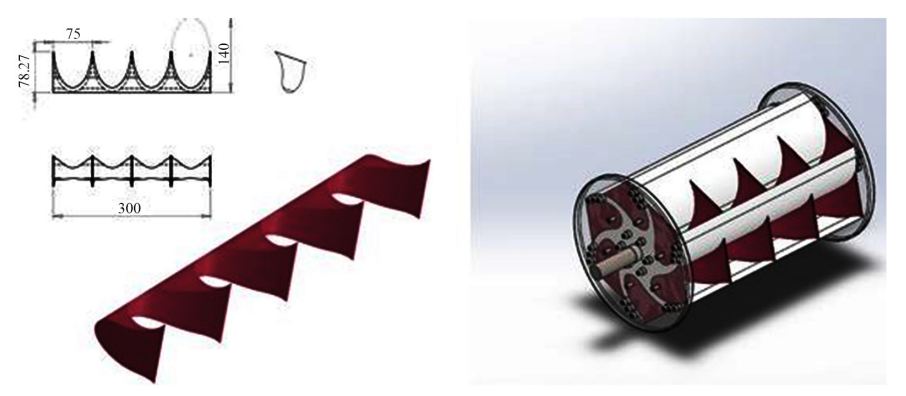

Figure 6. Drawing of the 4 cup insert and runner with 4 cup inserts.

\subsection{Accelerator Channel(s)}

The purpose of the accelerator channel(s) is to direct high-speed flow towards the runner. The accelerator channel consists of a $0.015 \mathrm{~m}$ thick stainless steel insert and acrylic sides. After analysing lower and higher thicknesses for the steel section in the initial stages of testing, it was concluded that the thickness of 0.015 $\mathrm{m}$ should be adopted and taken forward. Three different wedge designs were tested with the same thickness stainless steel inserts and are given below. The lengths of all wedges were adjusted to fit the laboratory spillway but they can be further elongated to fit specific sites. With the goal to test the influence of the accelerator channel width on the turbine's performance, the runner with 2 cup inserts was tested with a $0.15 \mathrm{~m}$ wide accelerator channel (A) shown in Figure 7 as well as a $0.126 \mathrm{~m}$ wide accelerator channel (B) shown in Figure 8. Channels A and $\mathrm{B}$ direct the flow towards the blades in the same manner as shown in Figure 7. The only notable difference between these two channels is the width. Whilst channel A's width-to-runner-ratio is 1:2 and channel B's width-to-runner-ratio is $1: 2.4$.

The runner with 4 cup inserts is tested with the channel (C) shown in Figure 9. The 4 cup insert diameter is $0.075 \mathrm{~m}$, same as the width of channel C. The runner with no cup inserts is also tested with the accelerator channel A.

\section{Laboratory Testing}

All tests are completed in the recirculating flume at Cardiff University, School of Engineering hydraulics laboratory. The flume is $1.2 \mathrm{~m}$ wide, $1 \mathrm{~m}$ deep and $17 \mathrm{~m}$ long. This flume has been used in previous laboratory experiments investigating hydrokinetic turbines [19] [20] [21]. At the flume inlet, a weir is installed in or- 
der to generate a difference in water elevation. At a height of $1 \mathrm{~m}$, a $0.3 \mathrm{~m}$ wide channel spillway is attached to the weir where water is discharged as soon as the weir-channel opening overspills. After a short horizontal section, the channel slope changes to $45^{\circ}$ in order to accelerate the flow and eventually drive the turbine runner as shown in Figure 10. All tests are conducted with discharges ranging from 6 to 16 1/s. The head ranges from 0.49 to $0.55 \mathrm{~m}$.
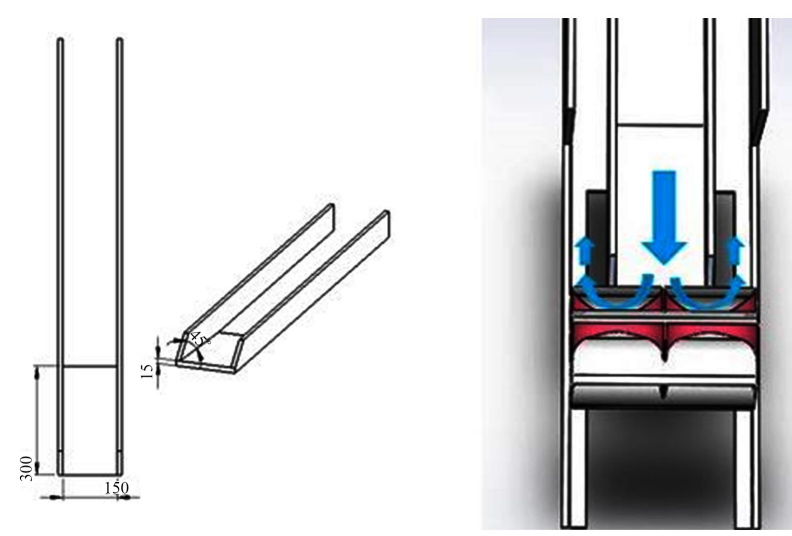

Figure 7. Accelerator channel A, $0.15 \mathrm{~m}$ wide.

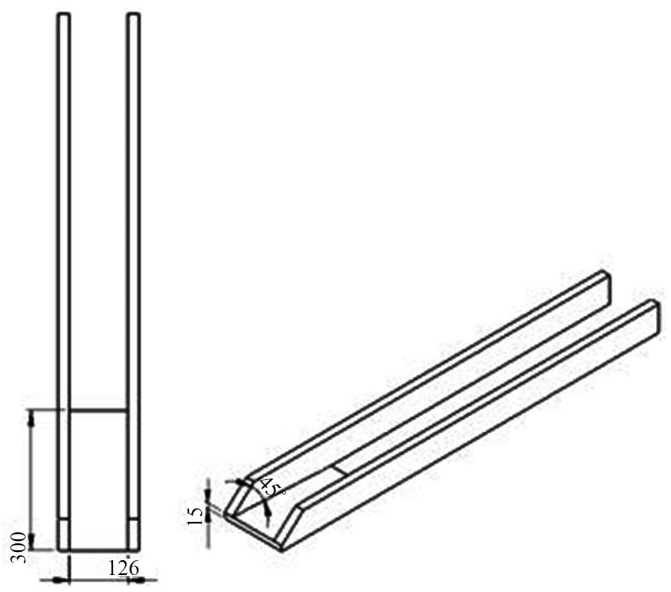

Figure 8. Accelerator channel B, $0.126 \mathrm{~m}$ wide.
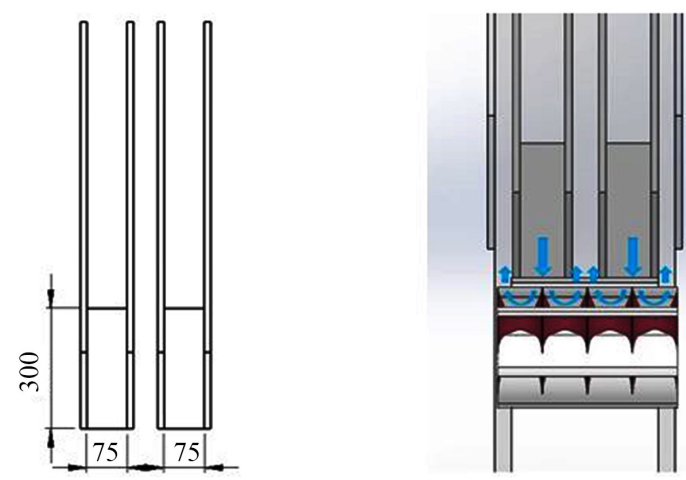

Figure 9. Accelerator channel C comprising two sections, each $0.075 \mathrm{~m}$ wide. 


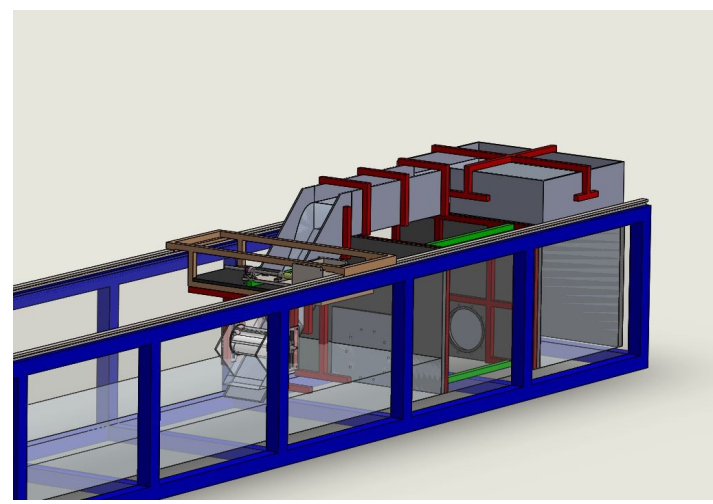

Figure 10. Spillway construction in the testing flume.

\subsection{Flow Discharge Measurement}

A fully contracted rectangular weir is placed $10 \mathrm{~m}$ downstream from the runner. It is used to measure the discharge of the flow. The weir is designed [22] with dimensions in millimetres shown in Figure 11. The discharge can be calculated using Equation (1) as follows [22]:

$$
Q=1.84\left(L-0.2 h_{\text {weir }}\right)\left(h_{\text {weir }}\right)^{3 / 2}
$$

where $h_{\text {weir }}$ represents the height of water above the weir opening in meters, $Q$ $\left(\mathrm{m} / \mathrm{s}^{3}\right)$ is discharge and $L(\mathrm{~m})$ is the width of the weir, which is $0.5 \mathrm{~m}$.

\subsection{Data Logging}

Data is logged to calculate the power of flow going into the system and the power produced by the turbine. The coefficient of power, or turbine efficiency is calculated by using Equation (2), which reads:

$$
C p=P_{\text {out }} / P_{\text {in }}
$$

where $P_{\text {in }}$ is the power of flow and $P_{\text {out }}$ is the power produced by the turbine. $P_{\text {in }}$ is obtained from:

$$
P_{\text {in }}=\rho g H Q
$$

with density of water $(\rho)$ is $\rho=1000 \mathrm{~m}^{3} / \mathrm{kg}$, gravitational constant $(g)$ is 9.81 $\mathrm{m}^{2} / \mathrm{s}, H$ is the head measured in meters and $Q$ is discharge obtained from the weir equation.

Torque $(T) \mathrm{s}$ measured in $\mathrm{Nm}$ and rotational velocity $(\omega)$ in $\mathrm{rad} / \mathrm{s}$ and hence $P_{\text {out }}$ can be calculated from:

$$
P_{\text {out }}=\mathrm{T} \omega
$$

The specific speed $N_{s}$ is calculated using Equation (5):

$$
N_{s}=N \sqrt{P_{\text {out }}} / H^{5 / 4}
$$

where $N$ is rotational speed in $\mathrm{rev} / \mathrm{min}, P_{\text {out }}$ is power produced by the turbine in $\mathrm{kW}$ and $H$ is effective head in $\mathrm{m}$. The speed factor $\varphi$ is calculated using Equation (6) where $\mathrm{D}$ is the diameter of the runner in $\mathrm{m}$ and $N$ and $H$ are the same as in Equation (5). 


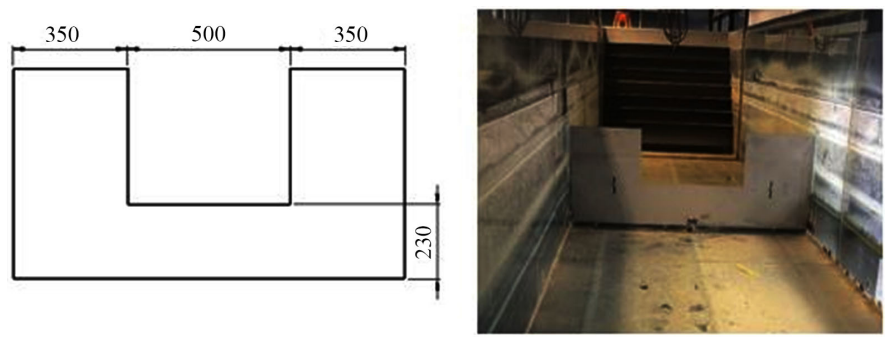

Figure 11. Rectangular weir used in the testing flume.

$$
\varphi=D N / 84.6 H^{0.5}
$$

For the power out (4) calculation, torque and the rotational velocity are measured with the torque transducer Futek TRS605.

\subsection{Turbine Drive Train Design}

The turbine laboratory set up consists of 4 main components which are shown in Figure 12 and are summarised below. The bridge, the drive train, the generator and the supporting structure components are kept the same throughout all tests. A movable bridge is used to support the drive train and the generator. The belt is tensioned by moving the bridge horizontally away from the runner in order to avoid belt slipping.

The drive train consists of 5 components as shown in Figure 13. The role of the drivetrain and generator are to transfer and convert mechanical rotational energy at the runner to electrical energy.

For the runner, a $20 \mathrm{~mm}$ stainless steel shaft is used with a 30 teeth pulley (4) placed at the end. A similar pulley is mounted at the end of the drive shaft (3). Both pulleys are connected with a Continental HTD 1500-5M timing belt (5) which transfers the rotational mechanical energy from the runner to the drive train. The torque transducer (2) is placed on the main shaft and is used for torque and rotational velocity measurements. At the very end of the main drive train shaft, a low speed AC generator (1) is mounted which converts the turbine system's mechanical energy into electrical energy. The entire process from the spinning of the runner to electricity generationis depicted in Figure 14.

\section{Results and Discussion}

More than 380 tests are completed in the laboratory. Early results and findings influence both the runner and the wedge design and have led to optimisations. The results are presented in terms of power coefficients calculated using Equation (2). As there are several geometrical parameters involved in the optimisation, a sketch of these is given in Figure 15. Variable " $x$ " represented the horizontal distance of the runner to the wedge, " $y$ " was the vertical distance of the runner to the flume bed and " $\mathrm{z}$ " was the perpendicular distance of the runner to the chute spillway. The overview of designs tested and their descriptions is shown in Table 1. 


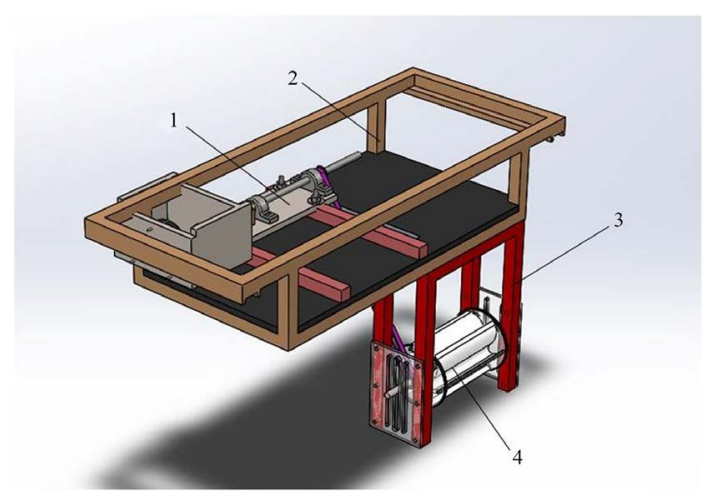

Figure 12. Spillway turbine testing structure: 1-drive train and generator, 2-bridge, 3-supporting structure, 4-runner.

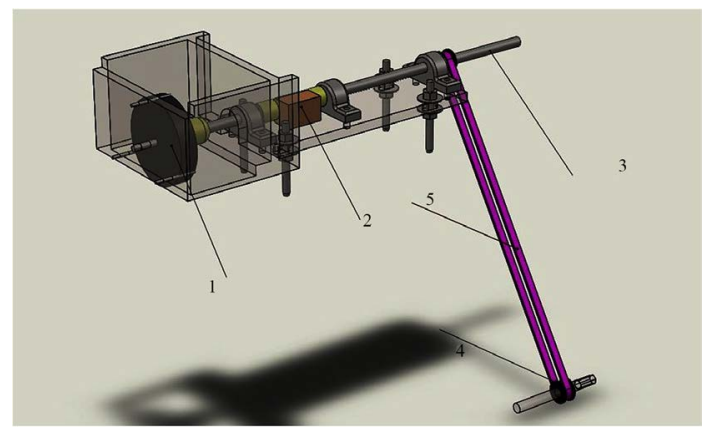

Figure 13. The drive train: 1-generator, 2-torque transducer, 3-drive train shaft, 4-pulley, 5-belt.
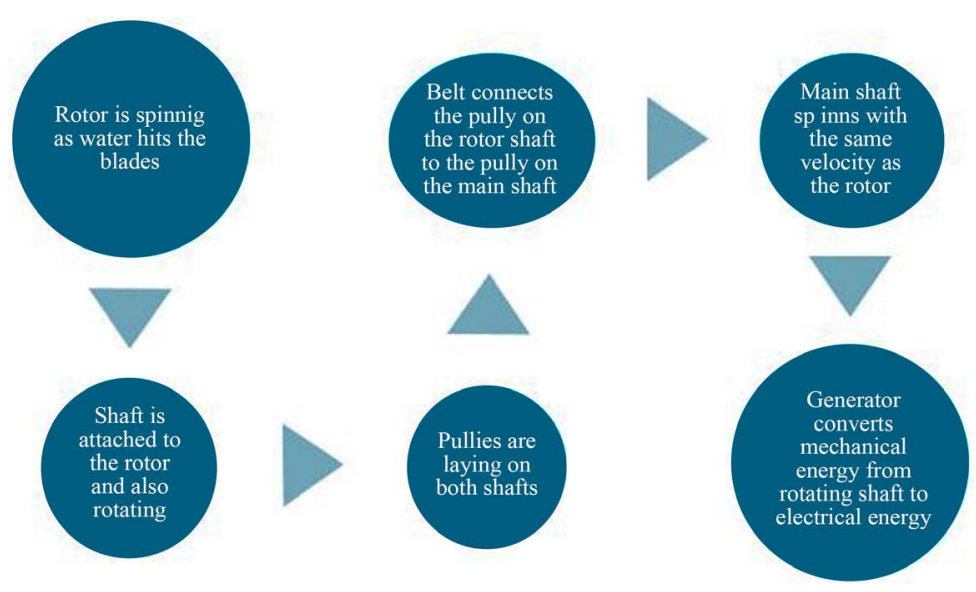

Figure 14. Mechanical to electrical energy conversion in the spillway turbine system.

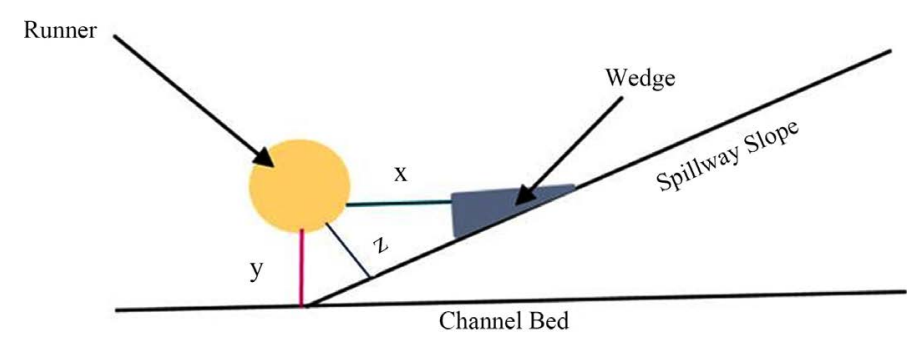

Figure 15. Sketch of geometrical parameters. 
Table 1. Descriptions of designs tested.

\begin{tabular}{|c|c|c|c|c|c|c|}
\hline & Channel A & Channel B & Channel C & Runner NC & Runner $2 \mathrm{C}$ & Runner 4C \\
\hline Description & $\begin{array}{l}0.15 \mathrm{~m} \text { wide, } \\
\text { tested with } \\
\text { runner } \mathrm{NC} \text { and } \\
\text { runner } 2 \mathrm{C} \text {. }\end{array}$ & $\begin{array}{l}0.126 \mathrm{~m} \\
\text { wide, tested } \\
\text { with runner } \\
2 \mathrm{C} \text {. }\end{array}$ & $\begin{array}{l}\text { Two part, } \\
0.075 \mathrm{~m} \\
\text { wide, tested } \\
\text { with runner } \\
4 \mathrm{C} \text {. }\end{array}$ & $\begin{array}{l}\text { Runner } \\
\text { with no cup } \\
\text { inserts } \\
\text { shown in } \\
\text { Figure } 5 \text {. }\end{array}$ & $\begin{array}{l}\text { Runner with } \\
2 \text { cup inserts } \\
\text { shown in } \\
\text { Figure } 6 .\end{array}$ & $\begin{array}{l}\text { Runner with } \\
4 \text { cup inserts } \\
\text { shown in } \\
\text { Figure } 7 .\end{array}$ \\
\hline
\end{tabular}

\subsection{Runner with 2 Cup Inserts}

Runner with 2 cup inserts (Runner 2C) is tested with accelerator channels A and $\mathrm{B}$. The results in terms of power coefficient as a function of torque produced of Runner $2 \mathrm{C}$ with channel A are shown in Figure 16 and Figure 17, and these show how changing the " $\mathrm{x}$ " and " $\mathrm{y}$ " geometric parameters affect turbine performance. Maximum efficiencies for power curves shown in Figure 18 are summarised in Table 2. The channel bed distance was increased to $0.385 \mathrm{~m}$ for results shown in Figure 19 and maximum efficiencies achieved for this setup are summarised in Table 3.

The runner performs best when it is placed $0.02 \mathrm{~m}$ from the wedge and 0.375 $\mathrm{m}$ from the channel bed achieving efficiency of $43.4 \%$. The efficiencies drop when the runner is moved away from the wedge in $\mathrm{x}$ direction and the channel bed in y direction, as it can be observed from Table 2 and Table 3.

This observation is also made when the runner with 2 semi-circular cup inserts is tested with channel B, which is narrower than channel A. Channel A and $B$ test results are plotted in Figure 18. The runner is placed $0.02 \mathrm{~m}$ from the wedge in $\mathrm{x}$ direction and $0.375 \mathrm{~m}$ from the channel bed in y direction for both cases, as this variable set up resulted in best turbine performance.

The maximum efficiency achieved with the $0.15 \mathrm{~m}$ wide channel (A) is $43.4 \%$ and the maximum efficiency attained with the $0.126 \mathrm{~m}$ wide channel (B) is $34.9 \%$. Therefore, it can be noted that runner $2 \mathrm{C}$ performs better with a wider channel than for a narrower channel, suggesting a channel-width-to-runner-width-ratio of 1:2 for the final design of the turbine.

\subsection{Runner with 4 Cup Inserts}

Runner 4C with the accelerator channel $C$ is tested with different " $x$ " and " $y$ " geometric parameters shown in Figure 15. A photo of this setup is shown in Figure 19.

The measured power curves for the $4 \mathrm{C}$ runner with different " $\mathrm{x}$ " and " $y$ " parameters are presented in Figure 20 and Figure 21. The power curves are shown in Figure 20, with a channel bed distance of $0.375 \mathrm{~m}$ and maximum power coefficients are given in Table 4. The channel bed distance is then increased to 0.385 $\mathrm{m}$ and the power curves are presented in Figure 21 and maximum efficiencies achieved for this setup are summarised in Table 5.

The runner with 4 cup semi-circular inserts performed best when it was placed $0.02 \mathrm{~m}$ from the wedge and $0.375 \mathrm{~m}$ from the channel bed achieving a maximum power coefficient (or efficiency) of $34.36 \%$. The efficiencies dropped 
when the runner was moved away from the wedge in " $\mathrm{x}$ " direction and the channel bed in " $y$ " direction, as it can be observed from Table 4 and Table 5.

Table 2. Maximum efficiencies from.

\begin{tabular}{cc}
\hline \multicolumn{2}{c}{ Distance to channel bed $(\mathrm{y})=0.375 \mathrm{~m}$} \\
\hline Channel A position $(\mathrm{x})$ & Maximum Efficiency \% \\
\hline $0.02 \mathrm{~m}$ & $43.38 \%$ \\
$0.03 \mathrm{~m}$ & $39.07 \%$ \\
\hline
\end{tabular}

Table 3. Maximum efficiencies from.

\begin{tabular}{cc}
\hline & Distance to channel bed $(\mathrm{y})=0.385 \mathrm{~m}$ \\
\hline Channel A position $(\mathrm{x})$ & Maximum Efficiency \% \\
\hline $0.02 \mathrm{~m}$ & $34.87 \%$ \\
$0.03 \mathrm{~m}$ & $32.16 \%$ \\
\hline
\end{tabular}

Table 4. Maximum efficiencies from.

\begin{tabular}{cc}
\hline & Distance to channel bed $(\mathrm{y})=0.375 \mathrm{~m}$ \\
\hline Wedge position $(\mathrm{x})$ & Maximum Efficiency $\%$ \\
\hline $0.02 \mathrm{~m}$ & $34.36 \%$ \\
$0.03 \mathrm{~m}$ & $29.49 \%$ \\
\hline
\end{tabular}

Table 5. Maximum efficiencies from.

\begin{tabular}{cc}
\hline & Distance to channel bed $(\mathrm{y})=0.385 \mathrm{~m}$ \\
\hline Wedge position $(\mathrm{x})$ & Maximum Efficiency \% \\
\hline $0.02 \mathrm{~m}$ & $20.64 \%$ \\
$0.03 \mathrm{~m}$ & $20.35 \%$ \\
\hline
\end{tabular}

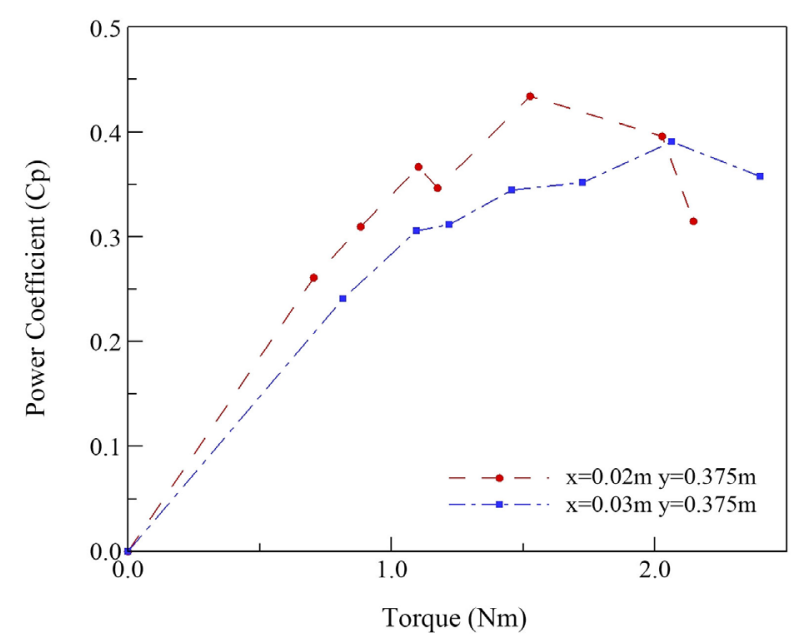

Figure 16. Power curve of Runner $2 \mathrm{C}$ and channel $\mathrm{A}$ at $\mathrm{y}=$ $0.375 \mathrm{~m}$ distance. 


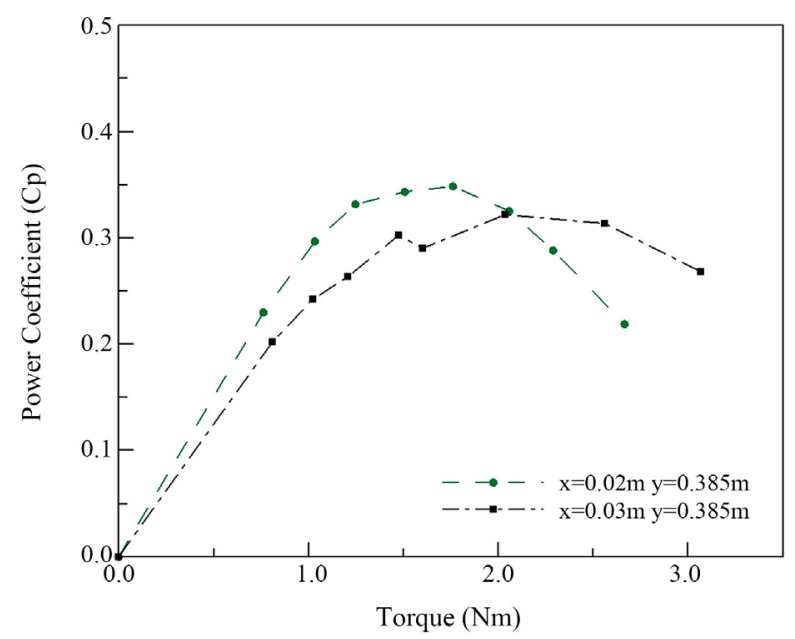

Figure 17. Power curve of Runner $2 \mathrm{C}$ and channel $\mathrm{A}$ at $\mathrm{y}=$ $0.385 \mathrm{~m}$ distance.

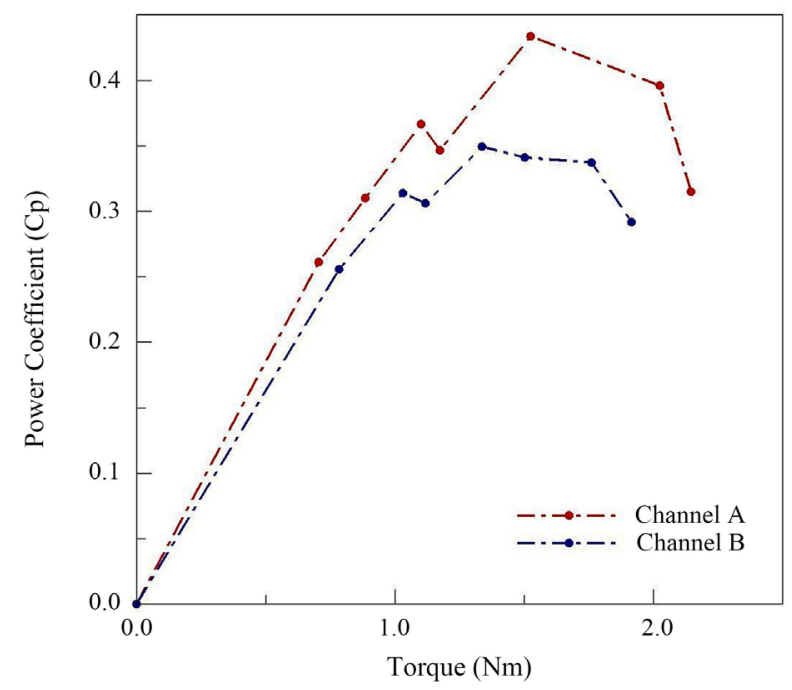

Figure 18. Runner $2 \mathrm{C}$ with accelerator channels $\mathrm{A}$ and $\mathrm{B}$.

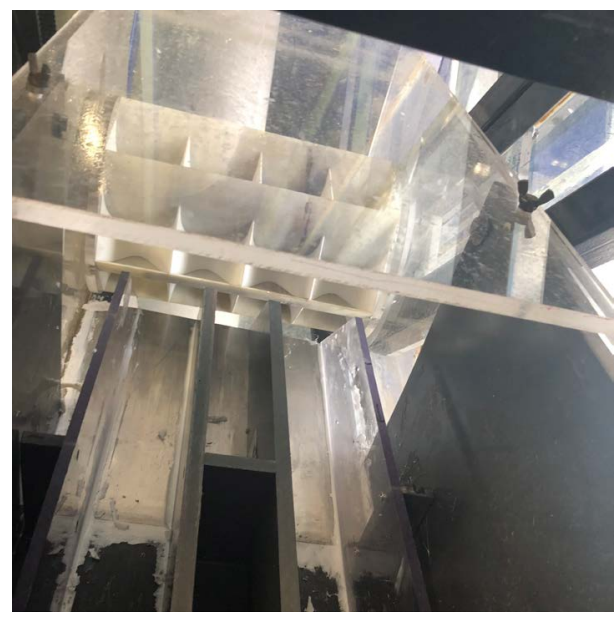

Figure 19. Laboratory testing of runner $4 \mathrm{C}$ and accelerator channel C. 


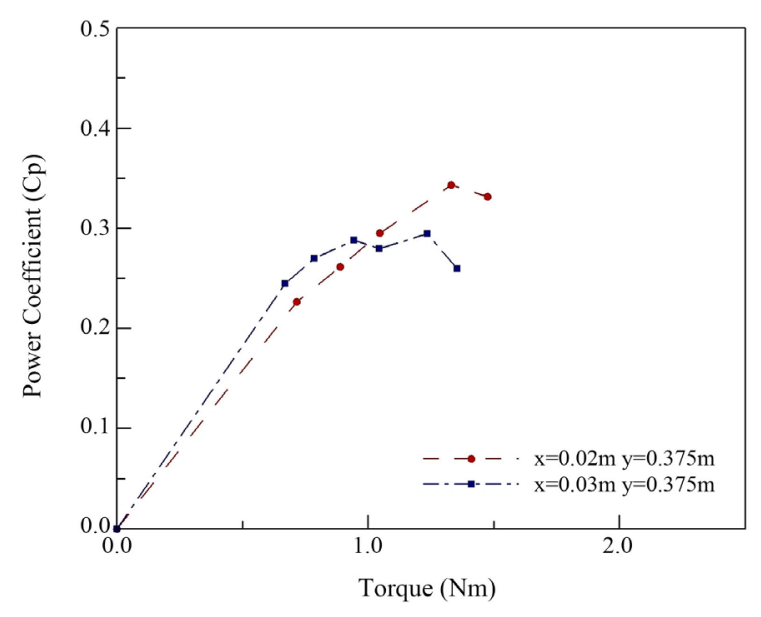

Figure 20. Power curve for Runner 4C and channel C with $y=0.375 \mathrm{~m}$.

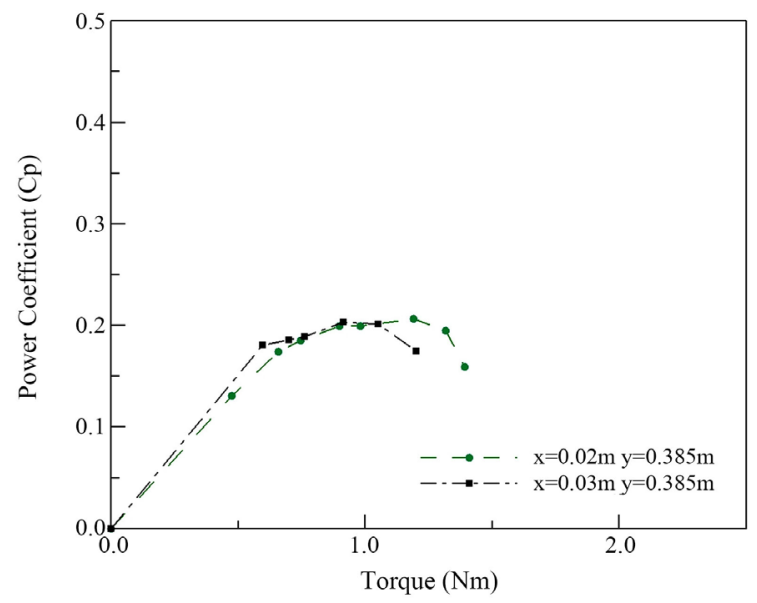

Figure 21. Power curve for Runner 4C and channel C with $y=0.385 \mathrm{~m}$.

\subsection{Runner with No Inserts}

Finally, the runner with no cup inserts is tested with the accelerator channel A in order to quantify the effect of the cup inserts on turbine performance.The peak power coefficient achieved with different " $x$ " and " $y$ " distances are summarized in Table 6.

From previously presented results it is noted that all runners performed best when placed $0.02 \mathrm{~m}$ horizontally from the wedge and $0.375 \mathrm{~m}$ from the channel bed. Hence, these parameters are used in the performance comparison plot of runner 2C, runner 4C and runner with no inserts which is presented in Figure 22.

It can be noted that the runner with 2 cup semi-circular inserts and $0.15 \mathrm{~m}$ wide channel A showed best performance from all setups tested. It is noteworthy that the turbine's performance is similar to recently investigated horizontal [23] [24] and vertical [19] [20] [21] axis hydrokinetic turbines and hence offers an opportunity to harness very shallow high-speed flows which were previously deemed unsuitable for hydrokinetic energy exploitation. 


\subsection{Specific Speed and the Speed Factor}

The specific speed and speed factors are calculated using Equations (5) and (6) respectively. The calculated values for peak power coefficients are given in Table 7. The speed factors against the power coefficient for all three runners are depicted in Figure 23.

From Figure 23 and Table 7 it can be noted that the runners with cup inserts have higher specific speeds and speed factors than the runner with no cup inserts. Hence, the idea of achieving similar water blade interaction as it occurs in Pelton blades shown in Figure 2 and Figure 3 is considered validated. As the speed factors fall into $0.43-0.48$ range of impulse turbine speed factors [11], it can be concluded that the spillway turbine with 2 cup inserts can be classified as an impulse turbine. The specific speed [25] range shown in Table 7 also confirms that the spillway turbine can be defined as an impulse turbine.

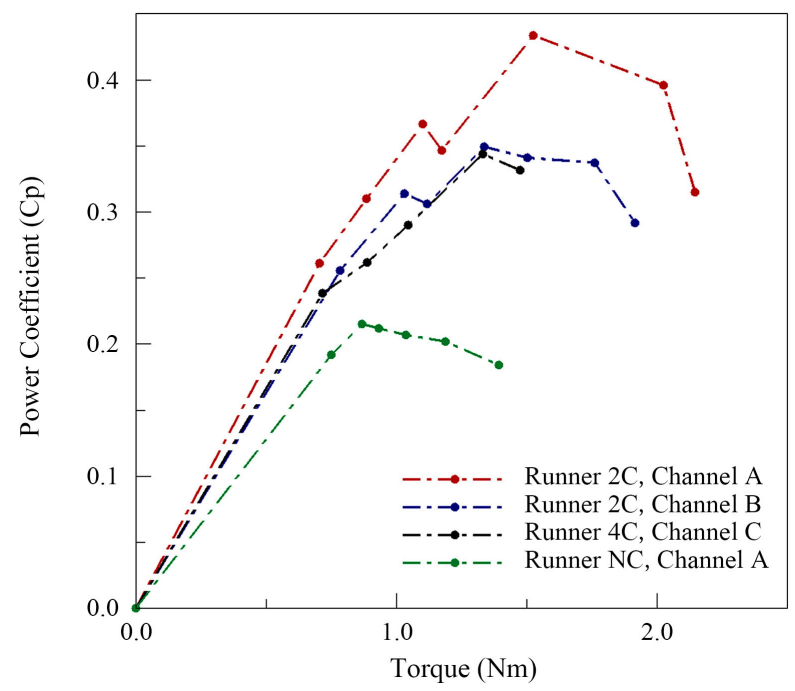

Figure 22. Comparison of all runners tested, $x=0.02 \mathrm{~m}$ and $\mathrm{y}=0.375 \mathrm{~m}$.

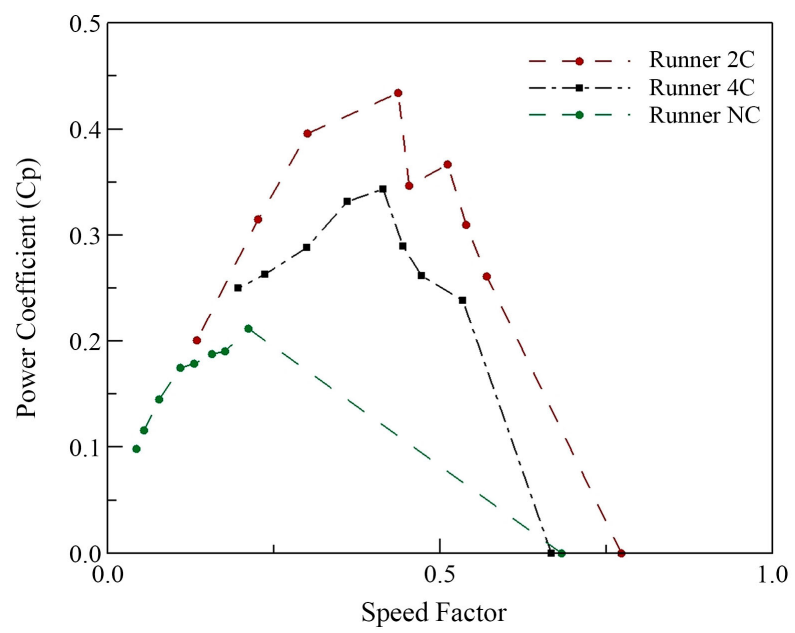

Figure 23. Speed factors of tested runners. 
Table 6. Runner with no inserts and channel A.

\begin{tabular}{cccc}
\hline \multicolumn{2}{c}{ Distance to channel bed $(\mathrm{y})=0.375 \mathrm{~m}$} & \multicolumn{2}{c}{ Distance to channel bed $(\mathrm{y})=0.385 \mathrm{~m}$} \\
\hline Wedge position (x) & Maximum Efficiency \% & Wedge position (x) & Maximum Efficiency\% \\
\hline $0.02 \mathrm{~m}$ & $22.43 \%$ & $0.02 \mathrm{~m}$ & $21.96 \%$ \\
$0.03 \mathrm{~m}$ & $22.03 \%$ & $0.03 \mathrm{~m}$ & $21.35 \%$ \\
\hline
\end{tabular}

Table 7. Speed factor and specific speeds.

\begin{tabular}{|c|c|c|c|}
\hline & Runner 2C, Channel A & Runner 4C, Channel A & Runner NC, Channel A \\
\hline Speed Factor $(\varphi)$ & 0.437 & 0.414 & 0.398 \\
\hline Specific Speed, Ns & 43.66 & 37.49 & 28.64 \\
\hline
\end{tabular}

\section{Conclusions}

A novel spillway turbine has been designed and experimentally tested in Cardiff University's hydraulics laboratory. The main components of the turbine are the 6-bladed runner and its cup inserts, combining the advantages of a Savonius freestream drag turbine and a Pelton turbine, the cups of which promote local flow reversal and thus improve the Savonius-type runner's efficiency.

The runner is placed downstream of an accelerator channel and the runner-width-to-channel-ratio is found to be an important geometric parameter too. The tests confirmed that a 1:2 ratio works better than a smaller ratio.

Furthermore, the influence of the number of cup inserts on the performance of the turbine has been tested, too. The design that shows the best efficiency is the 6-bladed runner with 2 semi-circular cup inserts.

The specific speeds and maximum speed factor obtained for the best performing runner, indicate that this turbine can be considered an impulse turbine. The specific speed and the speed factor are in the same range as a Pelton wheel's parameters.

The best performing design reached a peak efficiency of $43.4 \%$. The next step forward in the development of the spillway turbine will be testing a scaled-up version in a relevant environment.

\section{Acknowledgements}

The research and the first author are funded by Emrgy Inc. Atlanta which is gratefully acknowledged.

\section{Conflicts of Interest}

The authors declare no conflicts of interest regarding the publication of this paper.

\section{References}

[1] Gerland, P., et al. (2014) World Population Stabilization Unlikely This Century. Science, 346, 234-237. https://doi.org/10.1126/science.1257469 
[2] United Nations Framework Convention on Climate Change (2016) Paris Agreement. https://unfccc.int/sites/default/files/english paris agreement.pdf

[3] European Commission (2009) DIRECTIVE 2009/28/EC of the European Parliament and of the Council of 23 April 2009 on the Promotion of the Use of Energy from Renewable Sources and Amending and Subsequently Repealing Directives 2001/77/EC and 2003/30. Official Journal of the European Union, Belgium.

[4] European Commission (2019) EU Climate Action. https://ec.europa.eu/clima/citizens/eu en

[5] World Energy Council (2016) World Energy Resources. Hydropower. https://www.worldenergy.org/assets/downloads/1.-World-Energy-Issues-Monitor-2 017-Full-Report.pdf

[6] International Rivers (2019) Human Impacts of Dams. https://www.internationalrivers.org/human-impacts-of-dams

[7] Viollet, P.L. (2017) From the Water Wheel to Turbines and Hydroelectricity. Technological Evolution and Revolutions. Comptes Rendus Mecanique, 345, 570-580. https://doi.org/10.1016/j.crme.2017.05.016

[8] Lewis, B. (2014) Major Historical Development in the Design of Water Wheels and Francis Hydroturbines. IOP Conference Series. Earth and Environmental Science, 22, Article ID: 012020. https://doi.org/10.1088/1755-1315/22/1/012020

[9] Power Technology Energy News and Market Analysis (2019) Three Gorges Dam Hydro Electric Power Plant, China. https://www.power-technology.com/projects/gorges

[10] Itaipu Binacional (2019) Generating Units. https://www.itaipu.gov.br/en/energy/generating-units

[11] Douglas, J., Swaffield, J. and Gasiorek, J. (2001) Fluid Mechanics. 4th Edition, Pearson Education, Essex.

[12] Behrouzi, F., Maimun, A. and Nakisa, M. (2014) Review of Various Designs and Development in. Hydropower Turbines, 2, 87-91.

[13] Atthanayake, I. (2009) Analytical Study on Flow through a Pelton Turbine Bucket Using Boundary Layer Theory. International Journal of Engineering \& Technology, 9, 11-15.

[14] Zhang, Z. (2007) Flow Friction Theorem of Pelton Turbine Hydraulics. Proceedings of the Institution of Mechanical Engineers, Part A: Journal of Power and Energy, 221, 1173-1180. https://doi.org/10.1243/09576509JPE395

[15] Zhang, Z. (2009) Flow Dynamics of the Free Surface Flow in the Rotating Buckets of a Pelton Turbine. Proceedings of the Institution of Mechanical Engineers, Part A: Journal of Power and Energy, 223, 609-623. https://doi.org/10.1243/09576509JPE670

[16] Novak, P., Moffat A., Nalluri, C. and Narayanan, R. (1996) Hydraulic Structures. 2nd Edition, E \& F.N. Spon, London.

[17] Ecoursesonline.iasri.res.in (2019) SWCS: Lesson 21. Chute Spillway. http://ecoursesonline.iasri.res.in/mod/page/view.php?id=2189

[18] Gibson, J. (2019) Llyn Brianne Dam Spillway (C) John Gibson. Geograph.org.uk. https://www.geograph.org.uk/photo/925456

[19] Runge, S., Stoesser, T., Morris, E. and White, M. (2018) Technology Readiness of a Vertical-Axis Hydro-Kinetic Turbine. Journal of Power and Energy Engineering, 6, 63-85. https://doi.org/10.4236/jpee.2018.68004

[20] Priegue, L. and Stoesser, T. (2017) The Influence of Blade Roughness on the Per- 
formance of a Vertical Axis Tidal Turbine. Journal of Marine Energy, 17, 136-146. https://doi.org/10.1016/j.ijome.2017.01.009

[21] Ouro, P., Runge, S., Luo, Q. and Stoesser, T. (2019) Three-Dimensionality of the Wake Recovery behind a Vertical Axis Turbine. Renewable Energy, 133, 1066-1077. https://doi.org/10.1016/j.renene.2018.10.111

[22] British Standards (2017) BS ISO: 1438-Hydrometry-Open Channel Flow Measurement Using Thin-Plate Weirs. British Standards Institute, London.

[23] Ouro Barba, P., Harrold, M., Stoesser, T. and Bromley, P. (2017) Hydrodynamic Loadings on a Horizontal Axis Tidal Urbine Prototype. Journal of Fluids and Structures, 71, 78-95. https://doi.org/10.1016/j.jfluidstructs.2017.03.009

[24] Ouro, P. and Stoesser, T. (2018) Impact of Environmental Turbulence on the Performance and Loadings of a Tidal Stream Turbine. Flow, Turbulence and Combustion, 102, 613-639. https://doi.org/10.1007/s10494-018-9975-6

[25] Sangal, S., Garg, A. and Kumar, D. (2003) Review of Optimal Selection of Turbines for Hydroelectric Projects. International Journal of Emerging Technology and Advanced Engineering, 3, 424-430. 